\title{
Oxidative stress and immunotoxicity induced by graphene oxide in zebrafish
}

\author{
Minjie Chen ${ }^{\mathrm{a}}$, Junfa Yin ${ }^{\mathrm{b}}$, Yong Liang ${ }^{\mathrm{b}, \mathrm{c}}$, Shaopeng Yuan ${ }^{\mathrm{d}}$, Fengbang Wang ${ }^{\mathrm{b}}$, \\ Maoyong Song ${ }^{\mathrm{b}, \mathrm{c}, *}$, Hailin Wang ${ }^{\mathrm{a}}$ \\ a School of Medicine, Jianghan University, Wuhan 430056, PR China \\ b State Key Laboratory of Environmental Chemistry and Ecotoxicology, Research Center for Eco-Environmental Sciences, Chinese Academy of Sciences, \\ Beijing 100085, PR China \\ ${ }^{\mathrm{c}}$ Institute of Environment and Health, Jianghan University, Wuhan 430056, PR China \\ ${ }^{\mathrm{d}}$ Department of Pharmacology, Institute of Materia Medica, Chinese Academy of Medical Sciences and Peking Union Medical College, Beijing 100050, China
}

\section{A R T I C L E I N F O}

\section{Article history:}

Received 6 November 2015

Received in revised form 18 February 2016

Accepted 18 February 2016

Available online 22 February 2016

\section{Keywords:}

Graphene oxide

Acute toxicity

Zebrafish

Oxidative stress

Immunotoxicity

\begin{abstract}
A B S T R A C T
Graphene oxide (GO) has been extensively explored as a promising nanomaterial for applications in biology because of its unique properties. Therefore, systematic investigation of GO toxicity is essential to determine its fate in the environment and potential adverse effects. In this study, acute toxicity, oxidative stress and immunotoxicity of GO were investigated in zebrafish. No obvious acute toxicity was observed when zebrafish were exposed to $1,5,10$ or $50 \mathrm{mg} / \mathrm{L}$ GO for 14 days. However, a number of cellular alterations were detected by histological analysis of the liver and intestine, including vacuolation, loose arrangement of cells, histolysis and disintegration of cell boundaries. As evidence for oxidative stress, malondialdehyde levels and superoxide dismutase and catalase activities were increased and glutathione content was decreased in the liver after treatment with GO. GO treatment induced an immune response in zebrafish, as demonstrated by increased expression of tumor necrosis factor $\alpha$, interleukin-1 $\beta$, and interleukin- 6 in the spleen. Our findings demonstrated that GO administration in an aquatic system can cause oxidative stress and immune toxicity in adult zebrafish. To our knowledge, this is the first report of immune toxicity of GO in zebrafish.
\end{abstract}

(c) 2016 Elsevier B.V. All rights reserved.

\section{Introduction}

Graphene is a single-atom-thick, two-dimensional sheet of hexagonally arranged carbon atoms isolated from its threedimensional parent material, graphite (Geim and Novoselov, 2007; Kopelevich and Esquinazi, 2007). Because of their unique physicochemical properties, graphene and its derivatives have attracted tremendous research interest (Geim 2009; Allen et al., 2010). They have a great range of potential applications, including hydrogen storage (Wang et al., 2009), catalysis (Scheuermann et al., 2009) and as electrodes (Eda et al., 2008). Applications also exist in biomedical fields, such as cellular imaging (Wang et al., 2010), drug delivery (Sun et al., 2008), biosensing (Zhou et al., 2009; Akhavan et al., 2012), and photothermal therapy (Zhang et al., 2011a). Because of

\footnotetext{
* Corresponding author at: State Key Laboratory of Environmental Chemistry and Ecotoxicology, Research Center for Eco-Environmental Sciences, Chinese Academy of Sciences, Beijing 100085, PR China. Fax: +86 1062849178.

E-mail address: smsong@rcees.ac.cn (M. Song).
}

risk factors associated with the manufacture and use of these materials, the potential toxicity of graphene in biological systems is of significant concern (Sanchez et al., 2012; Seabra et al., 2014).

Graphene oxide (GO) is one of the most important graphene derivatives. By formation of hydrogen bonds between polar functional groups on the GO surface and water molecules, a stable GO colloidal suspension is attainable (Shih et al., 2012), suggesting that GO would have advantages over other carbon-based materials for biomedical applications (Bitounis et al., 2013). However, because of its greater solubility and stability in the environment or in serum-properties that prevent its aggregation-GO might have greater uptake when used in medical applications, making its toxicity a very important consideration.

Though studies have shown that nanomaterials might have deleterious side effects (Nel et al., 2006; Song et al., 2012; Song et al., 2013), few reports on GO toxicity have been published so far. Akhavan and Ghaderi (2010) investigated toxicity of GO against Gram-negative (such as Escherichia coli), and Gram-positive (such as Staphylococcus aureus) bacteria and found that it was effective for use in antibacterial materials. Bacterial cells lost membrane 
a)

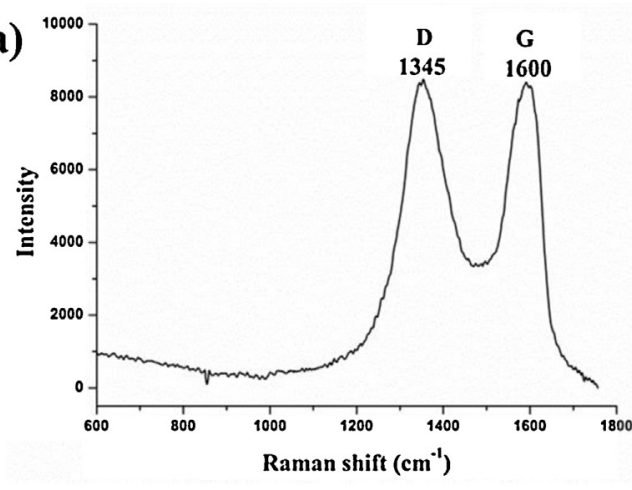



Fig. 1. Characterization of GO: Raman spectra (a), SEM image (b), and TEM images (c).


c)

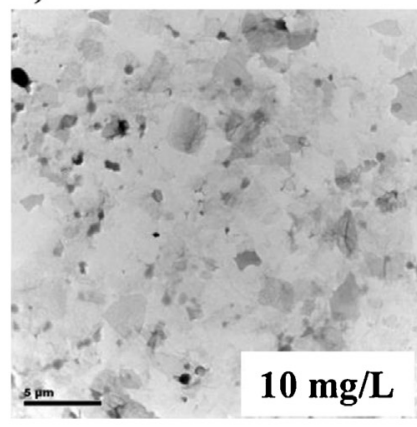

deionized water

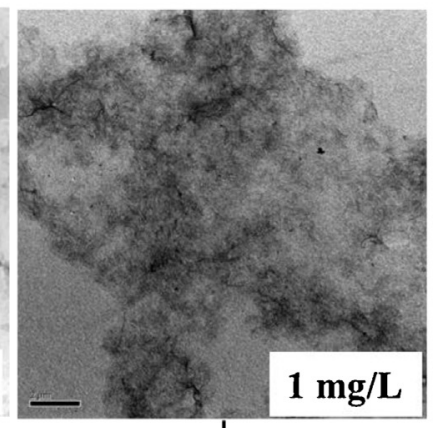

$1 \mathrm{mg} / \mathrm{L}$
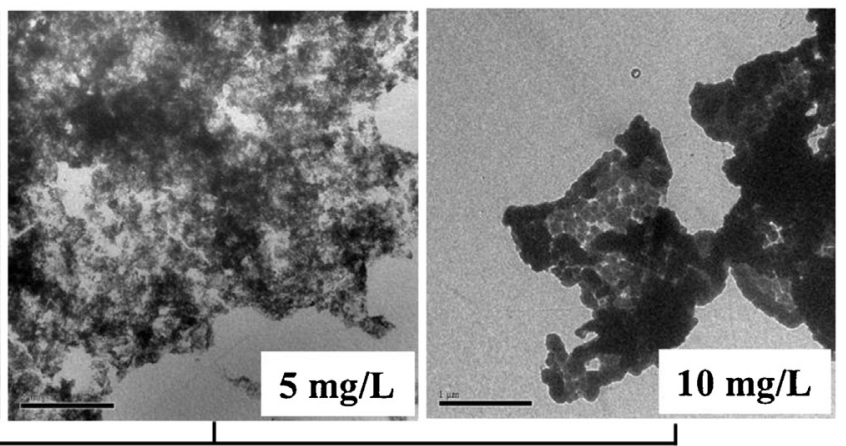

tap water

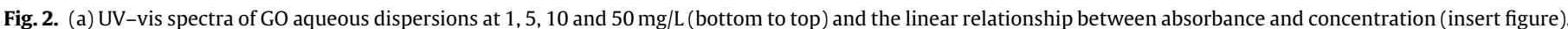

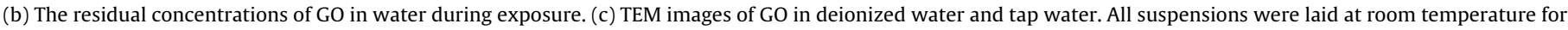
$24 \mathrm{~h}$, and were diluted to $1 \mathrm{mg} / \mathrm{L}$ for TEM image.

integrity upon exposure to GO (Tazawa et al., 2007) based on analysis by transmission electron microscopy (TEM). Interactions between dispersed GO sheets and target cells have been studied in monolayer cultures of lung epithelial cells (Chang et al., 2011) and fibroblasts (Wang et al., 2011). Single-layer GO sheets were internalized and sequestered in cytoplasmic membrane bound vacuoles by human lung epithelial cells or fibroblasts, and induced cytotoxicity at doses above $20 \mu \mathrm{g} / \mathrm{mL}$ after 24 h exposure (Zhang et al., 2010). When injected intravenously into mice, GO induced granulomas in the lungs, liver, spleen and kidney, and was lethal in 4 out of 9 animals (Hu et al., 2011; Wang et al., 2011). Zhang et al. (2011b) also noted deposition and retention of GO in the lungs along with lung tissue injury, inflammation, and granuloma formation in mice receiving intravenous GO. Thus, long-term adverse health effects of GO will need to be carefully considered with respect to design of its applications as well as its release into the environment.

Zebrafish is a powerful vertebrate model for in vivo studies of aquatic toxicology (Sawle et al., 2010). To better understand the potential toxicity of GO in zebrafish, we examined its effects on oxidative stress responses and the innate immune system, the latter as indicated by expression of the representative immunological genes tumor necrosis factor $\alpha$ (TNF- $\alpha$ ), interleukin- $\beta$ (IL-1 $\beta$ ) and interleukin-6 (IL-6). Knowledge about such effects of GO could help to ensure the safe application of this versatile material. Our results should offer insights into potential toxicity mechanisms of GO in aquatic ecosystems. 



Va: vacuolation

LA: loose arrangement of cells Di: disintegration of cell boundaries


arrangement of cells, and disintegration of cell boundaries was expressed by the number of "+".

\section{Materials and methods}

\subsection{Preparation and characterization of $G O$}

GO was synthesized by a modified Hummers method from natural graphite powder. Typically, $2 \mathrm{~g}$ graphite powder was added to concentrated $\mathrm{H}_{2} \mathrm{SO}_{4}(98 \%, 50 \mathrm{~mL})$ and stirred for $2 \mathrm{~h}$. Next, $10 \mathrm{~g}$ $\mathrm{KMnO}_{4}$ was added gradually, with stirring, and the temperature of the mixture maintained below $30^{\circ} \mathrm{C}$ for $3 \mathrm{~h}$. Distilled water $(150 \mathrm{~mL})$ was then added and the mixture stirred at room temperature for another $3 \mathrm{~h}$. The reaction was terminated by adding a solution of distilled water $(400 \mathrm{~mL})$ containing $\mathrm{H}_{2} \mathrm{O}_{2}(30 \%, 25 \mathrm{~mL})$. The mixture was washed three times with $1 \mathrm{M} \mathrm{HCl}$ in aqueous solution $(100 \mathrm{~mL}$ each $)$ and then washed four times with distilled water $(200 \mathrm{~mL}$ each). Exfoliation was conducted by sonicating a GO dispersion $(5 \mathrm{mg} / \mathrm{mL})$ using a power setting of $40 \mathrm{~W}$ for $4 \mathrm{~h}$. The resulted sample was centrifuged at $6000 \times g$ for $5 \mathrm{~min}$, and the upper solution collected for further experiments. The morphology of GO sheets was characterized under scanning electron microscopy (SEM) and TEM. In addition, Raman spectroscopy of GO was performed on an inVia Raman spectroscope (Renishaw plc, Wotton-under-Edge, U.K.) with a 532-nm laser source.

\subsection{Fish maintenance and exposure}

Healthy 2-month-old zebrafish were maintained in recirculating aquarium tanks at $28 \pm 0.5^{\circ} \mathrm{C}$ with a $12: 12$ light/dark cycle and fed twice daily with fresh Artemia nauplii. The fish were acclimated for 1 week prior to experiments. After acclimation, the fish were exposed to $0,1,5$ or $10 \mathrm{mg} / \mathrm{L}$ GO for $14 \mathrm{~d}$. Each treatment group was housed in duplicate 6 -L glass tanks ( $N=4$ tanks per group, 10 males and 10 females per tank). Half of the exposure water in each tank was renewed daily.

\subsection{Histology}

The gills, livers and intestines were collected for histological examination. Tissues were fixed in paraformaldehyde solution $(4 \%$, $\mathrm{w} / \mathrm{v}$ ) for $24 \mathrm{~h}$ then dehydrated in ethanol, embedded in paraffin, sectioned $(3 \mu \mathrm{m})$ and stained with hematoxylin and eosin. Each section was examined under a light microscope.

\subsection{Biochemistry}

Zebrafish were quickly euthanized in melting ice and the liver tissue was removed immediately. This was homogenized on ice with $200 \mu \mathrm{L}$ ice-cold physiological saline, then centrifuged at $4000 \times g$ at $4{ }^{\circ} \mathrm{C}$ for $15 \mathrm{~min}$ and the supernatant collected. Protein concentrations of these samples were determined with the Quick Start ${ }^{\mathrm{TM}}$ Bradford Protein Assay (Bio-Rad, California, USA). The supernatants were assayed for glutathione (GSH) and malondialdehyde (MDA) contents, using commercial kits following the manufacturer's protocols (Cayman Chemical, Ann Arbor, MI, USA).

Superoxide dismutase (SOD) and catalase (CAT) were measured according to Manikandan et al. (2010). Briefly, $100 \mu \mathrm{L}$ of liver homogenate was mixed with $750 \mu \mathrm{L}$ ethanol and $150 \mu \mathrm{L}$ 
chloroform (both solvents ice cold). Reaction mixtures were centrifuged at $4000 \times \mathrm{g}$ for $5 \mathrm{~min}$ at $4{ }^{\circ} \mathrm{C}$ and supernatants collected. Next, $500 \mu \mathrm{L} 0.6 \mathrm{mM}$ EDTA and $1 \mathrm{~mL}$ bicarbonate buffer $(0.1 \mathrm{M}, \mathrm{pH}$ 10.2 ) were added to $500 \mu \mathrm{L}$ of each supernatant. For SOD measurements, the reaction was initiated by the addition of $500 \mu \mathrm{L} 1.3 \mathrm{mM}$ epinephrine and absorbance was read at $480 \mathrm{~nm}$ against a reagent blank containing buffer instead of liver homogenate. SOD values were expressed as absorbance at $480 \mathrm{~nm}$. To assay CAT, $100 \mu \mathrm{L}$ liver homogenate was diluted to a total volume of $1.2 \mathrm{~mL}$ with sodium phosphate buffer (50 mM, pH 7.0) and mixed with $1 \mathrm{~mL} 30 \mathrm{mM}$ $\mathrm{H}_{2} \mathrm{O}_{2}$ solution. The optical density of each sample was measured at $240 \mathrm{~nm}$ for $3 \mathrm{~min}$ against a reagent blank containing buffer instead of liver homogenate. CAT values were expressed as absorbance at $240 \mathrm{~nm}$

\subsection{Gene expression assay}

The zebrafish spleens were homogenized in $1.0 \mathrm{~mL}$ Trizol reagent (Invitrogen, Carlsbad, CA, USA), and total RNA was extracted according the manufacturer's protocol. Total RNA ( $1 \mu \mathrm{g})$ was included in a reverse-transcription reaction to produce firststrand complementary DNA (cDNA) using the ImProm $\mathrm{Il}^{\mathrm{T}}$ Reverse Transcription System (Promega). IL-1 $\beta$, IL-6, and TNF- $\alpha$ expression were quantitated using SYBR green assays (Applied Biosystems) on the ABI 7500 Real-Time PCR system. Zebrafish $\beta$-actin was used as standard to control for the starting quantity of RNA. The sequences of PCR primers were: 5'-GAGGAGCACCCCGTCCTGCTCAC-3' and 5'-GATGGCTGGACCAGGGCCTCTGG-3' for $\beta$-actin, 5'-TGGCGA ACGTCATCCAAG-3' and 5'-GGAGCACTGGGCGACGCATA$3^{\prime}$ for IL-1 $\beta$, 5'-TCAACTTCTCCAGCGTGATG-3' and $5^{\prime}$-TCTTTCCCTCTTTTCCTCCTG-3' for IL-6, and 5'-GCTTATGAGCCATGCAGTGA-3' and 5'TGCCCAGTCTGTCTCCTTCT-3' for TNF- $\alpha$ (Yoon et al., 2013). PCR was performed with an initial denaturation of $5 \mathrm{~min}$ at $95^{\circ} \mathrm{C}$, then 35 cycles were run for $30 \mathrm{~s}$ of denaturation at $95^{\circ} \mathrm{C}, 30 \mathrm{sec}$ of annealing at $55^{\circ} \mathrm{C}$, and $30 \mathrm{~s}$ of extension at $72^{\circ} \mathrm{C}$. The cycle threshold (CT) value was calculated to indirectly assess relative changes in expression levels based on the $2^{-\Delta \Delta C T}$ method (Livak and Schmittgen, 2001).

\subsection{Data analysis}

SPSS statistical software (version 13.0) and Sigma Plot 10.0 were used for statistical analysis. Significant differences among control and various treatment groups were determined using a one-way analysis of variance and Tukey's multiple range test. Differences were statistically significant at $p<0.05$.

\section{Results}

\subsection{Characterization of $G O$}

In the Raman spectrum of GO, two peaks were visible corresponding to the $G$ band at $1600 \mathrm{~cm}^{-1}$, derived from the graphite structure, and the D band at $1345 \mathrm{~cm}^{-1}$, derived from defects (Fig. 1a). The morphology and structure of GO sheets were investigated with SEM and TEM. Fig. 1b shows a SEM image of GO, in which single flakes of GO were visible. The GO flakes had a crumpled and rippled structure with a morphology resembling a thin curtain. These parameters indicated very good exfoliation of graphite during the oxidation process. As indicates in Fig. 1c, showing TEM images, independent GO sheets were observed. Dark areas indicated the thick stacking nanostructure of several GO layers with the presence of some oxygen functional groups. Areas of higher trans- parency showed much thinner films of a few layers of GO, resulting from stacking nanostructure exfoliation.

\subsection{GO stability in suspension and its acute toxicity to zebrafish}

We exposed zebrafish to graded GO concentrations over a period of $14 \mathrm{~d}$, and monitored its survival. Survival of zebrafish in controls and all groups exposed to $\mathrm{GO}(1,5,10$ and $50 \mathrm{mg} / \mathrm{L})$ did not differ significantly $(p>0.05)$ (data not shown). However, the GO sheets tended to aggregate and precipitate over time. Megascopic precipitate was observed immediately after higher concentrations of GO were added to the exposure medium. To compare stability of GO suspensions during exposure, residual GO in the exposure medium was monitored by absorbance at its peak wavelength $(230 \mathrm{~nm}$ ) (Fig. 2a). As shown in Fig. 2b, the $50 \mathrm{mg} / \mathrm{L}$ suspension of GO showed a dramatic reduction in absorbance during the first few hours with a decrease to $21.4 \%$ and $7 \%$ of the initial mass value at 3 and $24 \mathrm{~h}$, respectively. The residual GO of the $10 \mathrm{mg} / \mathrm{L} \mathrm{GO}$ suspension decreased more gradually, to $64.3 \%$ at $24 \mathrm{~h}$. The 1 and $5 \mathrm{mg} / \mathrm{L}$ GO suspensions were more stable, with $86 \%$ and $94 \%$, respectively, remaining of the initial GO after $24 \mathrm{~h}$. The stability of GO in deionized water and tap water (exposure condition) was investigated using TEM (Fig. 2c). GO was dispersed in deionized water and were laid at room temperature for $24 \mathrm{~h}$. In this suspension, individual GO sheets were well distinguishable and appeared as single- or fewlayered sheets with the size less than $5 \mu \mathrm{m}$. GO dispersed in tap water was seen to be agglomerated into cluster where it was difficult to distinguish the GO sheets individually. Dark areas in TEM image of $10 \mathrm{mg} / \mathrm{L}$ GO suspension indicated GO with higher concentration tend to aggregate to the thick stacking nanostructure in tap water. Because these data indicated that they would provide the most reliable exposure, 1, 5 and $10 \mathrm{mg} / \mathrm{L} \mathrm{GO}$ were selected for subsequent experiments.

\subsection{Histopathology}

For histopathological analysis of adult zebrafish $14 \mathrm{~d}$ following GO exposure, control and GO exposed fish were anesthetized, sectioned and stained with hematoxylin and eosin. As shown in Fig. 3, there was no apparent damage to the gills of fish that were exposed to $\mathrm{GO}$ at any concentration $(1,5$ or $10 \mathrm{mg} / \mathrm{L})$, as compared with those of control fish (Fig. 3e-h). The most significant differences between control and GO exposed fish were observed in the liver and intestine. The normal liver is composed of a continuous mass of hepatocytes with a large number of blood sinusoids (Fig. 3a). The livers of fish exposed to GO showed vacuolation, loose arrangement of hepatic cells, histolysis, and disintegration of cell boundaries (Fig. 3b-d). The damage was more severe and progressive with higher GO concentrations. Compared with controls, vacuolation, loose arrangement of intestinal epithelium, histolysis and disintegration of cell boundaries were observed in the intestines of GO exposed zebrafish. In addition, the number of goblet cells increased with higher GO concentrations (Fig. 3i-1).

\subsection{Analysis of oxidative stress markers}

As shown in Fig. 4, exposure to GO, in a concentrationindependent manner, caused a significant change in levels of MDA and GSH and in enzymatic activities of SOD and CAT. Effects of GO on MDA content in zebrafish are illustrated in Fig. 4a. MDA content was significantly increased in fish exposed to 1,5 , or $10 \mathrm{mg} / \mathrm{L} \mathrm{GO}$ relative to control fish $(p<0.05)$ on day 1 . There were no significant differences in MDA levels between GO treated and control zebrafish on days 4,8 , and 14 , except for in those treated with $1 \mathrm{mg} / \mathrm{L} \mathrm{GO}$ on day 4. As shown in Fig. 4b, exposure to GO caused a significant decrease $(p<0.05)$ in GSH levels on days 1 and 4 . However on day 

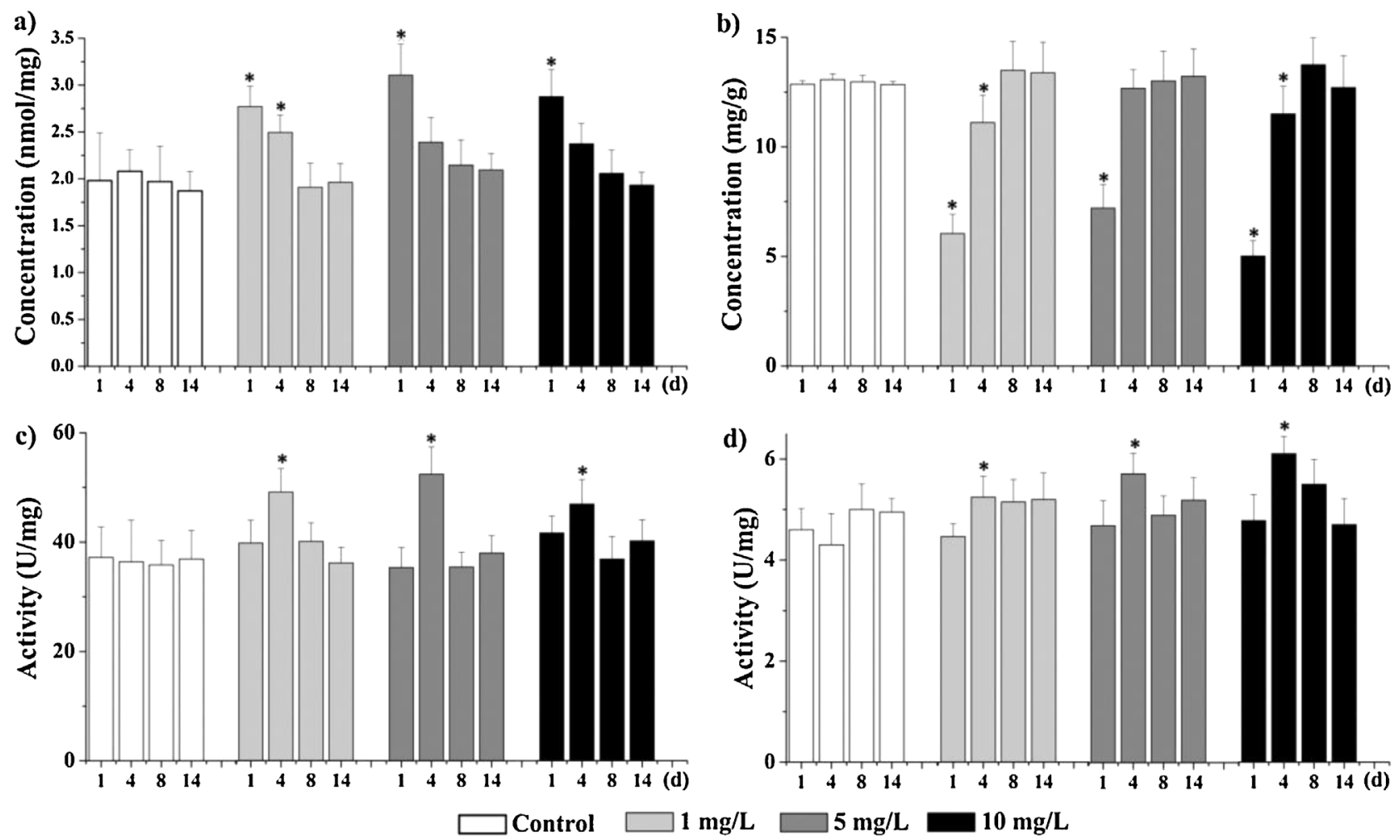


Statistically significant differences from the corresponding exposure day control values are indicated by ${ }^{*}, p<0.05$.

4, there was no effect in the group receiving $5 \mathrm{mg} / \mathrm{L}$ GO. GSH levels in GO treated zebrafish were closer to control levels on days 8 and 14. Significantly increased $(p<0.05)$ SOD and CAT activities were observed in all GO exposure groups as compared with in controls (Fig. 4c and d) on day 4. Both enzymatic activities were no different, however, in GO treated and control zebrafish on days 1, 8, and 14.

\subsection{Gene expression of proinflammatory cytokines}

The response to inflammatory challenge was analyzed by monitoring expression of proinflammatory cytokines in spleen samples from GO treated zebrafish. Semi-quantitative RT-PCR was performed to evaluate TNF- $\alpha$, IL-1 $\beta$ and IL- 6 expression. Expression levels of IL-1 $\beta$ and IL- 6 after $14 \mathrm{~d}$ exposure to GO were significantly increased in a GO dose-dependent manner (Fig. 5a and b). IL-1 $\beta$ and IL-6 expression was 4.2 and 3.7-fold higher, respectively, in the spleens of zebrafish treated with $10 \mathrm{mg} / \mathrm{mL} \mathrm{GO}$, as compared with in control fish $(p<0.05)$. However, TNF- $\alpha$ expression was significantly elevated only in the group receiving $5 \mathrm{mg} / \mathrm{L} \mathrm{GO}$ (Fig. $5 \mathrm{c}$, $p<0.05)$.

\section{Discussion}

To use GO in real world applications, it will be essential to confirm its biocompatibility and toxicity through extensive in vitro and in vivo studies. GO can cause toxicological effects, as suggested in a number of reports using both in vivo and in vitro tests (Sanchez et al., 2012; Seabra et al., 2014). Because natural aquatic systems are more complex than the simpler experimental systems used for such toxicity studies, few reports so far have investigated effects of GO on aquatic organisms. Depending on $\mathrm{pH}$, ionic strength, concentration and dissolved organic matter GO can aggregate or agglomerate in an aquatic environment (Schniepp et al., 2008; Patra et al., 2009). Because aggregation or agglomeration of GO can change its size, effective surface area, and other physicochemical properties, it may affect its toxicity by making it difficult to control the actual exposure concentrations. We found that higher concentrations of GO were more likely to aggregate during exposure. This may have influenced GO uptake, distribution, and toxicity. For example, the concentrations of residual GO in the 10 - and $50-\mathrm{mg} / \mathrm{L}$-treated groups were similar after $8 \mathrm{~h}$ exposure. Such factors may explain why GO was toxic to zebrafish in a concentration-independent manner in this study.

Though the mechanisms responsible for GO toxicity have been discussed previously, no conclusions were reached that were sufficient to establish risk assessments or regulations (Gurunathan et al., 2013a; Gurunathan et al., 2013b). Oxidative stress is a mechanism of toxicity for various nanoparticles and is caused by generation of reactive oxygen species (ROS) in target cells. It has been suggested that ROS generation is one of the mechanisms of GO toxicity (Sanchez et al., 2012; Seabra et al., 2014). Normal cellular homeostasis reflects a balance between the level of ROS generation and ROS elimination or reduction by antioxidant enzymes. ROS levels are maintained by the action of SOD, CAT, or GSH peroxidase; when levels of ROS cannot be reduced by these cellular antioxidant activities, there may be adverse effects, such as membrane peroxidation, loss of ions, protein cleavage, and DNA strand breakage (Di Giulio et al., 1989). In a study on the possible toxicity of GO toward alveolar macrophages and alveolar epithelial cells, Duch et al. (2011) demonstrated that GO induced cytotoxicity, through ROS generation, resulted in impaired mitochondrial respiration and cell apoptosis. In another study, GO was toxic to MCF-7 cells in a dose-dependent manner, decreasing cell viability, increasing ROS generation, and causing lactate dehydrogenase release.

In our study, oxidative markers and antioxidant enzyme activities were used to evaluate GO-induced oxidative stress in zebrafish. We found that MDA levels were significantly elevated in GO treated groups on day 1 . Because MDA is the product of the reaction 


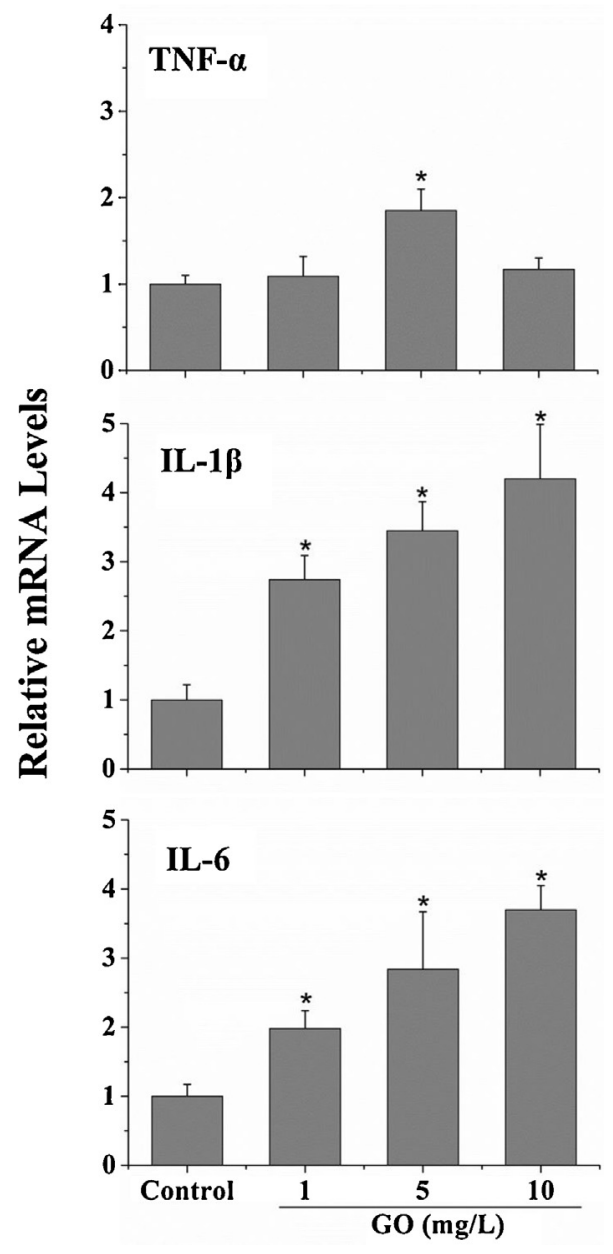

Fig. 5. mRNA expression levels of TNF- $\alpha$, IL-1 $\beta$ and IL-6 in spleens from zebrafish after 14 days exposure to $\mathrm{GO}(1,5$ and $10 \mathrm{mg} / \mathrm{L})$. Values are means $\pm \mathrm{SD}(n=4)$. Statistically significant differences from the control group are indicated by ${ }^{*}, p<0.05$.

between free radicals and unsaturated fatty acids in cell membranes, this indicated that the increase in lipid peroxidation in the liver of zebrafish exposed to GO was attributable to ROS production. Simultaneously, we observed that GSH levels were significantly reduced in GO treated groups on day 1 . The glutathione system is a key nonenzymatic mechanism to scavenge residual free radicals generated from oxidative metabolism and those not decomposed by antioxidant enzymes (El-Shenawy, 2010). The observed decrease in GSH may reflect its sulfhydryl group becoming oxidized by ROS to form the corresponding oxidized disulfide compound. Consistent with our observation, it was reported that increased MDA and decreased GSH contents were induced by other types of environmental oxidative stressors (Wu et al., 2011a; Zhao et al., 2013).

Oxidative toxicity of nanoparticles was reported to activate or inhibit several antioxidant enzymes (Griffitt et al., 2007; Ma et al., 2010). SOD and CAT form a vital first-line defense system against oxidative toxicity (Yu, 1994). SOD is crucial in converting superoxide radials to $\mathrm{H}_{2} \mathrm{O}_{2}$, then CAT facilitates removal of $\mathrm{H}_{2} \mathrm{O}_{2}$, metabolizing it to molecular oxygen and water (Daoud et al., 2012). In our study, GO treated zebrafish showed significantly increased SOD and CAT activities on day 4. GO exposure stimulated both CAT and SOD activities, suggesting that the $\mathrm{H}_{2} \mathrm{O}_{2}$ generated by SOD was directly removed by CAT. Consistent with our observations, others have reported increased SOD and CAT activities in zebrafish and Japanese medaka fish in response to oxidative stress caused by chemicals or nanoparticles (Wu et al., 2011a; Xiong et al., 2011).
Other studies reported decreased antioxidant enzyme activities, and attributed these to direct inhibitory effects of chemicals or nanoparticles on antioxidant enzymes (Wu et al., 2011b; Gomes et al., 2011). However, we did not observe such inhibition of SOD and CAT in our study. Furthermore, we observed that MDA and GSH contents and SOD and CAT activities in GO treated zebrafish returned to control levels with prolonged GO exposure. This might have indicated an eventual rebalancing of ROS generation and elimination in the zebrafish.

The oxidative stress response is of great importance in metabolizing toxicants and protecting hepatocytes in the liver (Bainy et al., 1996). We investigated the effects of GO on several organs of the zebrafish. Our observations indicated that GO accumulation occurred in the liver and intestine. There were obvious chronic toxicity responses in these organs after 14 days exposure. Histopathological analysis revealed that GO exposure caused dose-dependent damage to the liver and intestine of zebrafish, characterized by vacuolation, loose arrangement of hepatic or intestinal epithelial cells, histolysis, and disintegration of cell boundaries. These results indicated that GO ingested by zebrafish through diet may be deposited not only in the intestine but also may be transported to other organs by diffusion and blood circulation.

In recent reports, ROS produced at the wound site was described as an important cue for acute recruitment of leukocytes during injury-induced inflammation (Yoo et al., 2011; Deng et al., 2012). Other publications indicated that ROS acted as signaling molecules to trigger proinflammatory cytokine production (Nakahira et al., 2011; Zhou et al., 2011). For example, Bulua et al. (2011) showed that mitochondrial ROS influenced IL-6 transcription in cell culture and in a mouse model. Such data led us to further analyze expression of inflammatory cytokines, including TNF- $\alpha$, IL- $1 \beta$, and IL-6, in zebrafish exposed to GO. These are cytokines primarily produced during the innate immune response. GO exposure resulted in upregulation of these cytokines in zebrafish, indicating induction of an inflammatory response. Zhou et al. (2011) and Nakahira et al. (2011) demonstrated that, after an inflammatory stimulus, accumulation of damaged mitochondria precipitated an increase in mitochondrial ROS production which, in turn, enhanced inflammasome activation. Together, these findings suggest that GO exposure can simultaneously induce ROS generation and an inflammatory response in zebrafish. To our knowledge, this is first report of GOinduced immune toxicity in zebrafish.

\section{Conclusions}

This study demonstrated toxicity in zebrafish caused by GO exposure. We found that: (1) GO could cause toxic effects despite its tendency to aggregate in suspensions during exposure; (2) oxidative stress and tissue damage were induced in fish by GO through ROS, as indicated by the biomarkers MDA, GSH, SOD and CAT; and (3) GO caused immunotoxicity in fish as indicated by increased expression of inflammatory cytokines, TNF- $\alpha$, IL-1 $\beta$ and IL-6.

\section{Acknowledgements}

This work was supported by the National Basic Research Program of China (2014CB932000), the National Natural Science Foundation of China (Grant Nos. 21377146 and 21422705), the Strategic Priority Research Program of the Chinese Academy of Sciences (Grant No. XDB14010300), and the State Key Laboratory of Freshwater Ecology and Biotechnology (Grant No. 2014FB07).

\section{References}

Akhavan, O., Ghaderi, E., Rahighi, R., 2012. Toward single-DNA electrochemical biosensing by graphene nanowalls. ACS Nano 6, 2904-2916. 
Akhavan, O., Ghaderi, E., 2010. Toxicity of graphene and graphene oxide nanowalls against bacteria. ACS Nano 4, 5731-5736.

Allen, M.J., Tung, V.C., Kaner, R.B., 2010. Honeycomb carbon: a review of graphene. Chem. Rev. 110, 132-145.

Bainy, A.C.D., Saito, E., Carvalho, P.S.M., Junqueira, V.B.C., 1996. Oxidative stress in gill erythrocytes, liver and kidney of Nile tilapia (Oreochromis niloticus) from a polluted site. Aquat. Toxicol. 34, 151-162.

Bitounis, D., Ali-Boucetta, H., Hong, B.H., Min, D.-H., Kostarelos, K., 2013. Prospects and challenges of graphene in biomedical applications. Adv. Mater. 25, 2258-2268.

Bulua, A.C., Simon, A., Maddipati, R., Pelletier, M., Park, H., Kim, K.Y., Sack, M.N., Kastner, D.L., Siegel, R.M., 2011. Mitochondrial reactive oxygen species promote production of proinflammatory cytokines and are elevated in TNFR1-associated periodic syndrome (TRAPS). J. Exp. Med. 208, 519-533.

Chang, Y., Yang, S.T., Liu, J.H., Dong, E., Wang, Y., Cao, A., Liu, Y., Wang, H., 2011. In vitro toxicity evaluation of graphene oxide on A549 cells. Toxicol. Lett. 200, 201-210.

Daoud, A., Saud, A., Sudhir, K., Maqusood, A., Maqsood, A.S., 2012. Oxidative stress and genotoxic effect of zinc oxide nanoparticles in freshwater snail Lymnaea luteola L. Aquat. Toxicol. 124-125, 83-90.

Deng, Q., Harvie, E.A., Huttenlocher, A., 2012. Distinct signaling mechanisms mediate neutrophil attraction to bacterial infection and tissue injury. Cell. Microbiol. 14, 517-528.

Di Giulio, R.T., Washburn, P.C., Wenning, R.J., 1989. Biochemical responses in aquatic animals: a review of determinants of oxidative stress. Environ. Toxicol. Chem. 8, 1103-1123.

Duch, M.C., Budinger, G.R.S., Liang, Y.T., Soberanes, S., Urich, D., Chiarella, S.E., Campochiaro, L.A., Gonzalez, A., Chandel, N.S., Hersam, M.C.H., Mutlu, G.M., 2011. Minimizing oxidation and stable nanoscale dispersion improves the biocompatibility of graphene in the lung. Nano Lett. 11, 5201-5207.

Eda, G., Fanchini, G., Chhowalla, M., 2008. Large-area ultrathin films of reduced graphene oxide as a transparent and flexible electronic material. Nat. Nanotechnol. 3, 270-274.

El-Shenawy, N.S., 2010. Effects of insecticides fenitrothion, endosulfan and abamectin on antioxidant parameters of isolated rat hepatocytes. Toxicol. In Vitro 24, 1148-1157.

Geim, A.K., 2009. Graphene: status and prospects. Science 324, 1530-1534.

Geim, A.K., Novoselov, K.S., 2007. The rise of graphene. Nat. Mater. 6, 183-191.

Gomes, T., Pinheiro, J.P., Cancio, I., Pereira, C.G., Cardoso, C., Bebianno, M.J., 2011. Effects of copper nanoparticles exposure in the Mussel Mytilus galloprovincialis. Environ. Sci. Technol. 45, 9356-9362.

Griffitt, R.J., Weil, R., Hyndman, K.A., Denslow, N.D., Powers, K., Taylor, D., Barber, D.S., 2007. Exposure to copper nanoparticles causes gill injury and acute lethality in zebrafish (Danio rerio). Environ. Sci. Technol. 41, 8178-8186.

Gurunathan, S., Han, J.W., Eppakayala, V., Kim, J.H., 2013a. Green synthesis of graphene and its cytotoxic effects in human breast cancer cells. Int. J. Nanomed. 8, 1015-1027.

Gurunathan, S., Han, J.W., Eppakayala, V., Kim, J.H., 2013b. Biocompatibility of microbially reduced graphene oxide in primary mouse embryonic fibroblast cells. Colloids Surf. B: Biointerfaces 105, 58-66.

Hu, W., Peng, C., Lv, M., Li, X., Zhang, Y., Chen, N., Fan, C., Huang, Q., 2011. Protein corona-mediated mitigation of cytotoxicity of graphene oxide. ACS Nano 5 , 3693-3700.

Kopelevich, Y., Esquinazi, P., 2007. Graphene physics in graphite. Adv. Mater. 19, 4559-4563.

Livak, K.J., Schmittgen, T.D., 2001. Analysis of relative gene expression data using real-time quantitative PCR and the 2-DDCT Method. Methods 25, 402-408.

Ma, L.L., Liu, J., Li, N., Wang, J., Duan, Y.M., Yan, J.Y., Liu, H.T., Wang, H., Hong, F.S., 2010. Oxidative stress in the brain of mice caused by translocated nanoparticulate $\mathrm{TiO}_{2}$ delivered to the abdominal cavity. Biomaterials 31 , 99-105.

Manikandan, R., Thiagarajan, R., Beulaja, S., Sudhandiran, G., Arumugam, M., 2010 Effect of curcumin on selenite-induced cataractogenesis in Wistar rat pups. Curr. Eye Res. 35, 122-129.

Nakahira, K., Haspel, J.A., Rathinam, V.A.K., Lee, S.-J., Dolinay, T., Lam, H.C., Englert, J.A., Rabinovitch, M., Cernadas, M., Kim, H.P., Fitzgerald, K.A., Ryter, S.W., Choi, A.M., 2011. Autophagy proteins regulate innate immune responses by inhibiting the release of mitochondrial DNA mediated by the NALP3 inflammasome. Nat. Immunol. 12, 222-230.

Nel, A., Xia, T., Madler, L., Li, N., 2006. Toxic potential of materials at the nanolevel. Science 311, 622-627.

Patra, N., Wang, B., Kral, P., 2009. Nanodroplet activated and guided folding of graphene nanostructures. Nano Lett. 9, 3766-3771.
Sanchez, V.C., Jachak, A., Hurt, R.H., Kane, A.B., 2012. Biological interactions of graphene-family nanomaterials: an interdisciplinary review. Chem. Res. Toxicol. 25, 15-34.

Sawle, A.D., Wit, E., Whale, G., Cossins, A.R., 2010. An information-rich alternative: chemicals testing strategy using a high definition toxicogenomics and zebrafish (Danio rerio) embryos. Toxicol. Sci. 118, 128-139.

Scheuermann, G.M., Rumi, L., Steurer, P., Bannwarth, W., Mülhaupt, R., 2009. Palladium nanoparticles on graphite oxide and its functionalized graphene derivatives as highly active catalysts for the Suzuki-Miyaura coupling Reaction. J. Am. Chem. Soc. 131, 8262-8270.

Schniepp, H.C., Kudin, K.N., Li, J.L., Prudhomme, R.K., Car, R., Saville, D.A., Aksay, I.A. 2008. Bending properties of single functionalized graphene sheets probed by atomic force microscopy. ACS Nano 2, 2577-2584.

Seabra, A.B., Paula, A.J., de Lima, R., Alves, O.L., Duraín, N., 2014. Nanotoxicity of graphene and graphene oxide. Chem. Res. Toxicol. 27, 159-168.

Shih, C.J., Lin, S., Sharma, R., Strano, M.S., Blankschtein, D., 2012. Understanding the pH-dependent behavior of graphene oxide aqueous solutions: a comparative experimental and molecular dynamics simulation study. Langmuir 28 , 235-241.

Song, M.Y., Yuan, S.P., Yin, J.F., Wang, X.L., Meng, Z.H., Wang, H.L., Jiang, G.B., 2012. Size-dependent toxicity of nano-C60 aggregates: more sensitive indication by apoptosis-related Bax translocation in cultured human cells. Environ. Sci. Technol. 46, 3457-3464.

Song, M.Y., Zeng, L.Z., Yuan, S.P., Yin, J.F., Wang, H.L., Jiang, G.B., 2013. Study of cytotoxic effects of single-walled carbon nanotubes functionalized with different chemical groups on human MCF7 cells. Chemosphere 92, 576-582.

Sun, X., Liu, Z., Welsher, K., Robinson, J.T., Goodwin, A., Zaric, S., Dai, H., 2008. Nano-graphene oxide for cellular imaging and drug delivery. Nano Res. 1, 203-212.

Tazawa, H., Tatemichi, M., Sawa, T., Gilibert, I., Ma, N., Hiraku, Y., Donehower, L.A., Ohgaki, H., Kawanishi, S., Ohshima, H., 2007. Oxidative and nitrative stress caused by subcutaneous implantation of a foreign body accelerates sarcoma development in Trp53+/-mice. Carcinogenesis 28, 191-198.

Wang, K., Ruan, J., Song, H., Zhang, J., Wo, Y., Guo, S., Cui, D., 2011. Biocompatibility of graphene oxide. Nanoscale Res. Lett. 6, 8-15.

Wang, L., Lee, K., Sun, Y.Y., Lucking, M., Chen, Z., Zhao, J.J., Zhang, S.B., 2009. Graphene oxide as an ideal substrate for hydrogen storage. ACS Nano 3, 2995-3000

Wang, Y., Li, Z., Hu, D., Lin, C.T., Li, J., Lin, Y., 2010. Aptamer/graphene oxide nanocomplex for in situ molecular probing in living cells. J. Am. Chem. Soc. 132, 9274-9276.

Wu, M., Xu, H., Shen, Y., Qiu, W., Yang, M., 2011a. Oxidative stress in zebrafish embryos induced by short-term exposure to bisphenol A nonylphenol, and their mixture. Environ. Toxicol. Chem. 30, 2335-2341.

Wu, M., Xu, H., Yang, M., Xu, G., 2011b. Effects of chronic bisphenol A exposure on hepatic antioxidant parameters in medaka (Oryzias latipes). Toxicol. Environ. Chem. 93, 270-278.

Xiong, D., Fang, T., Yu, L., Sima, X., Zhu, W., 2011. Effects of nano-scale $\mathrm{TiO}_{2}$, ZnO and their bulk counterparts on zebrafish: acute toxicity, oxidative stress and oxidative damage. Sci. Total Environ. 409, 1444-1452.

Yoo, S.K., Starnes, T.W., Deng, Q., Huttenlocher, A., 2011. Lyn is a redox sensor that mediates leukocyte wound attraction in vivo. Nature 480, 109-112.

Yoon, Y., Yoon, J., Jang, M.Y., Na, Y., Ko, Y., Choi, J.H., Seok, S.H., 2013. High cholesterol diet induces IL-1 $\beta$ expression in adult but not larval zebrafish. PLoS One 8, e66970.

Yu, B.P., 1994. Cellular defenses against damage from reactive oxygen species. Physiol. Rev. 74, 139-162.

Zhang, W., Guo, Z., Huang, D., Liu, Z., Guo, X., Zhong, H., 2011a. Synergistic effect of chemo-photothermal therapy using PEGylated graphene oxide. Biomaterials 32, 8555-8561.

Zhang, X., Yin, J., Peng, C., Hu, W., Zhu, Z., Li, W., Fan, C., Huang, Q., 2011 b. Distribution and biocompatibility studies of graphene oxide in mice after intravenous administration. Carbon 49, 986-995.

Zhang, Y., Ali, S.F., Dervishi, E., Xu, Y., Li, Z., Casciano, D., Biris, A.S., 2010. Cytotoxicity effects of graphene and single-wall carbon nanotubes in neural phaeochromocytoma-derived PC12 cells. ACS Nano 4, 3181-3186.

Zhao, X., Wang, S., Wu, Y., You, H., Lv, L., 2013. Acute ZnO nanoparticles exposure induces developmental toxicity, oxidative stress and DNA damage in embryo-larval zebrafish. Aquat. Toxicol. 136-137, 49-59.

Zhou, M., Zhai, Y., Dong, S., 2009. Electrochemical sensing and biosensing platform based on chemically reduced graphene oxide. Anal. Chem. 81, 5603-5613.

Zhou, R., Yazdi, A.S., Menu, P., Tschopp, J., 2011. A role for mitochondria in NLRP3 inflammasome activation. Nature 469, 221-225. 